\title{
miR-203 is involved in the laryngeal carcinoma pathogenesis via targeting VEGFA and Cox-2
}

This article was published in the following Dove Press journal:

OncoTargets and Therapy

26 July 2016

Number of times this article has been viewed

\author{
$\operatorname{Lin} X u^{\prime}$ \\ Bin Shen ${ }^{2}$ \\ Tingting Chen ${ }^{3}$ \\ Pin Dong ${ }^{2}$ \\ 'Department of Otolaryngology, \\ Second Affiliated Hospital of Zhejiang \\ University Medical College, Hangzhou, \\ ${ }^{2}$ Department of Otolaryngology- \\ Head \& Neck Surgery, Shanghai \\ Jiaotong University Affiliated \\ First People's Hospital, Shanghai, \\ ${ }^{3}$ Lishui Central Hospital, Lishui, \\ Zhejiang Province, People's Republic \\ of China
}

Correspondence: Bin Shen

Department of Otolaryngology - Head \&

Neck Surgery, Shanghai Jiao Tong

University Affiliated First People's

Hospital, 100 Haining Road, Shanghai

200080, People's Republic of China

Email binshen1982@sohu.com

\begin{abstract}
The development of laryngeal squamous cell carcinoma (LSCC) is a multistep process involving multiple factors. MicroRNAs, a group of important negative regulators of gene expression, have also been confirmed to be involved in the LSCC pathogenesis. In the present study, we compared the expression of nine selected microRNAs in the LSCC tissues and adjacent nontumor tissues. We found that the expression of miR-203 was significantly reduced in the LSCC tissues. Predicted by using bioinformatics tools, we found that VEGFA and cyclooxygenase-2 (Cox-2) may be direct targets of $m i R-203$. By subsequent determination through dual-luciferase assay and Western blot, we confirmed that miR-203 suppresses the expression of VEGFA and Cox-2 by directly targeting 3 '-untranslated region. Meanwhile, by analyzing the relationship between $m i R$-203 and VEGFA in clinical tissue samples, we found that a negative correlation existed in the expression of $m i R$-203 and VEGFA $(P=0.0096, r=-0.33)$. Similarly, the expression of $m i R-203$ and Cox- 2 also has a negative correlation $(P=0.0019$, $r=-0.46)$. Subsequently, in vitro functional study indicated that $m i R-203$ played as a tumor suppressor by repressing proliferation, migration, and invasion of Hep-2 cells. The overexpression of VEGFA partially rescued the effect of overexpressed $m i R-203$. Overexpressed Cox-2 partially rescued the effect of $m i R-203$ on Hep- 2 cell proliferation but not on the cell migration and invasion capacity. These findings suggest that miR-203 plays as a tumor suppressor in LSCC, partially by regulating VEGFA and Cox-2, and may serve as a potential target for therapeutic intervention.
\end{abstract}

Keywords: non-coding RNA, laryngeal squamous cell carcinoma, correlation analysis

\section{Introduction}

Head and neck cancer is the seventh most common form of cancer in the world, which is composed of oral cavity, oropharynx, hypopharynx, and larynx cancers. ${ }^{1,2}$ Laryngeal cancer is considered to be the most common malignant neoplasm in the head and neck region. In 2008, an estimate of 151,000 new cases of laryngeal cancer was diagnosed worldwide. In the same year, it was responsible for 82,000 deaths worldwide. ${ }^{2}$ Meanwhile, although early stage laryngeal cancer is often cured by surgery or radiotherapy, for the majority of patients with the advanced disease, the outcome has not improved in the last three decades. This implies that significant health benefits could be achieved via effective prevention and treatment strategies.

MicroRNA (miRNA) is a kind of short noncoding RNAs that suppress the expression of protein-coding genes by partial complementary binding, especially to the 3'-untranslated regions (UTRs) of messenger RNAs. Alterations in MiRNA expression are involved in the initiation, progression, and metastasis of human cancer, and it is believed that miRNAs function both as tumor suppressors and as oncogenes in cancer development. ${ }^{3,4}$ Accumulating studies have shown that disturbed expression 
of miRNAs is involved in the cancer pathogenesis and drug resistance. ${ }^{5,6}$ Recently, increased reports indicated that disturbed miRNA levels existed in the laryngeal cancer and played very important roles in the pathogenesis of laryngeal cancer. ${ }^{7-9}$ However, the functional study is at the early stage and almost all the results needed to be confirmed in larger populations. Therefore, in this study, we detected the expression of nine miRNAs in laryngeal cancer tissues and examined the function of $m i R-203$ on cell proliferation, migration, and invasion.

\section{Patients and methods}

\section{Tissue samples}

Patients were enrolled in the period between July 2010 and June 2013. A total of 60 patients with laryngeal squamous cell carcinoma (LSCC) who underwent partial or total laryngectomy at the Department of Otolaryngology - Head \& Neck Surgery, Shanghai Jiao Tong University Affiliated First People's Hospital were included in the study. No chemotherapy and radiation were applied to the patients before the operation. The matched specimens of LSCC and the corresponding adjacent nonneoplastic tissues obtained from the patients were preserved in liquid nitrogen within 5 minutes of excision and then transported frozen to the laboratory and stored briefly at $-80^{\circ} \mathrm{C}$. The study was approved by the Ethics Committee of Shanghai Jiao Tong University Affiliated First People's Hospital, and written informed consent was obtained from all the participants.

\section{RNA isolation and quantitative reverse transcription-polymerase chain reaction}

Quantitative reverse transcription-polymerase chain reaction (qRT-PCR) analysis was used to determine the relative expression levels of selected miRNAs. Total RNA was extracted from the tissue samples by using TRIzol (Thermo Fisher Scientific, Waltham, MA, USA) according to the manufacturer's instructions. Random six RNA samples were mixed as one sample for the detection of target molecules as the preliminary experiment. The levels of $m i R-203$ in the samples of every patient were detected subsequently. The miRNAs expression was detected by TaqMan miRNA RT-Real-Time PCR. Single-stranded complementary DNA was synthesized by using TaqMan MicroRNA Reverse Transcription Kit (Thermo Fisher Scientific) and then amplified by using TaqMan Universal PCR Master Mix (Thermo Fisher Scientific) together with miRNA-specific TaqMan MGB probes (Thermo Fisher Scientific). The U6 snRNA was used for normalization. Each sample in each group was measured in triplicate, and the experiment was repeated at least three times for the detection of miRNAs.

\section{Cell culture}

Hep-2 and HEK293T cells were cultured in Dulbecco's Modified Eagle's Medium (DMEM) containing 10\% fetal bovine serum (HyClone, Logan, UT, USA), $100 \mathrm{IU} / \mathrm{mL}$ penicillin, and $10 \mathrm{mg} / \mathrm{mL}$ streptomycin. All cells were maintained at a temperature of $37^{\circ} \mathrm{C}$ under an atmosphere of $5 \% \mathrm{CO}_{2}$.

\section{Western blot}

Protein extracts were boiled in sodium dodecyl sulfate/ $\beta$-mercaptoethanol sample buffer, and $30 \mu \mathrm{g}$ samples were loaded into each lane of $10 \%$ polyacrylamide gels. The proteins were separated by electrophoresis, and the proteins in the gels were blotted onto polyvinylidene difluoride membranes (Amersham Pharmacia Biotech, St Albans, Herts, UK) by electrophoretic transfer. The membranes were incubated with rabbit anti-vascular endothelial growth factor A VEGFA polyclonal antibody (ab51745; Abcam, Cambridge, MA, USA) with a dilution of 1:2,000, rabbit anti-Cox-2 polyclonal antibody (Abcam) with a dilution of 1:5,000, or mouse anti- $\beta$-actin monoclonal antibody (sc-47778; Santa Cruz Biotechnology Inc., Dallas, TX, USA) with a dilution of $1: 3,000$ for 2 hours at $37^{\circ} \mathrm{C}$. The specific protein-antibody complex was detected by using horseradish peroxidase-conjugated goat antirabbit or rabbit antimouse IgG. Detection by the chemiluminescence reaction was carried out using the ECL kit (Pierce, Appleton, WI, USA). The $\beta$-actin signal was used as a loading control.

\section{Dual-luciferase assay}

A 435 bp segment of VEGFA 3'-UTR and a 1132 bp segment of Cox-2 were cloned into downstream of firefly luciferase coding region in the pGL3 control vector (Promega Corporation, Fitchburg, WI, USA) to generate luciferase reporter vector. For luciferase reporter assays, HEK293T cells were seeded in 48-well plates. One of the luciferase reporter vectors was cotransfected with miR-203 into HEK293T cells by using lipofectamine 2000 (Thermo Fisher Scientific). After 48 hours, the cells were harvested and assayed with the Dual-Luciferase Assay (Promega Corporation). Each treatment was performed in triplicate in three independent experiments. The results were expressed as relative luciferase activity (Firefly luciferase/Renilla luciferase).

\section{Cell proliferation assay}

Hep- 2 cells were seeded in 96-well plates at low density $\left(5 \times 10^{3}\right)$ in DMEM culture and allowed to attach overnight. The cells 
were then transfected with $m i R-203$ mimic or inhibitor, with sequence scrambled single-strand or double-strand short RNA as control. In all, $20 \mu \mathrm{L}$ of 3-(4,5-dimethylthiazol2-yl)-2,5-diphenyltetrazolium bromide (MTT; $5 \mathrm{mg} / \mathrm{mL}$; Sigma-Aldrich Co., St Louis, MO, USA) was added into each well after 48 hours of transfection, and the cells were incubated for further 4 hours. The absorbance was recorded at A570 nm with a 96-well plate reader after the dimethyl sulfoxide addition.

\section{Cell migration and invasion assays}

Hep-2 cells were transfected with the miR-203 mimic or inhibitor with scramble RNA as control. The transfected cells were harvested and subjected to the following assays after 48 hours of transfection. For migration assays, the transfected cells $\left(5 \times 10^{4}\right.$ cells $\left./ \mathrm{mL}\right)$ were seeded in the top of an $8.0 \mathrm{~mm}$-pore membrane chamber (Corning Incorporated, Corning, NY, USA). Following a 12-hour incubation period, the cells that passed through the membrane to attach to the bottom of the membrane were fixed and stained with hematoxylin and eosin (Sigma-Aldrich Co.). The cells were scraped and removed from the top of the chamber. The membranes were mounted on cover slides, and cells were counted. Cell migration was quantified by counting the amount of cells passing through the pores from five different fields per sample at $100 \times$ selected in a random manner. Cell invasion assays were carried out using modified Boyden chambers in 24-well tissue culture plates at $5 \times 10^{4}$ cells/well (BD Biosciences, San Jose, CA, USA). All experiments were performed in duplicate.

\section{Statistical analysis}

The results of independent two groups were analyzed by using $t$-test, and the correlation analysis was analyzed by $\chi^{2}$ test. All the data were analyzed by using SPSS Statistical Package Version 16 (SPSS Inc., Chicago, IL, USA). $P<0.05$ was considered statistically significant.

\section{Results}

\section{Expression of miR-203 is reduced in LSCC tissues}

MiRNAs is a group of gene expression suppressors, and disturbed miRNAs expression has been found in the LSCC tissues. To investigate the roles of miRNAs in the pathogenesis of LSCC, we first selected nine miRNAs that were reported to have disturbed expression in the LSCC patients. $^{7-9}$ Subsequently, total RNA was extracted from the LSCC tissues and adjacent nontumor tissues and every six RNA samples were mixed into one group. The expressions of miRNAs were detected by using stem-loop qRT-PCR.
As shown in Figure 1, the expression of miR-203 was reduced significantly $(P=0.0020)$ compared with the adjacent nontumor control. Since $m i R-203$ has significant lower expression in tumor samples, the level of miR-203 in every tumor and adjacent nontumor samples was detected by qRT-PCR subsequently. The correlation of $m i R-203$ and clinic pathological parameters was analyzed. Lower $m i R-203$ expression was also found in the T3-T4 stage LSCC compared with T1-T2, and more reduced $m i R-203$ expression was related to lymph node metastasis (Table 1).

\section{miR-203 suppresses the expression of VEGFA and Cox- 2 by targeting $3^{\prime}$-UTR}

To understand the roles of reduced $m i R-203$ in the pathogenesis of LSCC, we first predicted the target genes of $m i R-203$ by using online bioinformatics tool: TargetScan (http://www.targetscan.org). ${ }^{10}$ To our surprise, VEGFA and Cox-2, the overexpression of whom has been found to be positively correlated with the malignancy of LSCC, are the direct feasible targets of $m i R-203$ (Figures 2 and 3). ${ }^{10-13}$ To examine whether these two genes are the real target of $m i R-203$, we employed the dual-luciferase reporter system. A 334 bp segment of VEGFA or 1138 bp segment of Cox-2 containing the putative target sites of $m i R-203$ was subcloned into pGLO3 control vector, under the firefly luciferase coding region to generate the reporter plasmids. HEK293T cells were cotransfected with one of the reporter vectors and $m i R-203$ mimics or antagonist, with $\mathrm{pRL}-\mathrm{TK}$ which expression renilla luciferase as transfection control. The expression of $m i R-203$ was detected by qRT-PCR (Figures $2 \mathrm{~B}$ and $3 \mathrm{~B}$ ). Compared with the miRNA control, the luciferase activity was significantly suppressed by the miR-203, $45.7 \%(P<0.01)$. Furthermore, the luciferase activity was significantly upregulated by the $m i R-203$ inhibitor compared with the inhibitor control, $\sim 12.5 \%(P<0.05)$. These results indicate that $m i R-203$ targets the 3 '-UTR of VEGFA, leading to the change in the translation of firefly luciferase. Similar results were obtained when using Cox-2 reporter vector. Compared with the miRNA control, the luciferase activity was significantly suppressed by the $m i R-203, \sim 44.1 \%(P<0.05)$. Furthermore, the luciferase activity was significantly upregulated by the $m i R-203$ inhibitor compared with the inhibitor control, $\sim 18.5 \%(P<0.05)$.

Seed sequence mutation clones were also used to further confirm the binding site for $m i R-203$ (Figures 2D and 3D). The vector contains putative miR-203 binding region in the 3 '-UTR of VEGFA with four mutant nucleotides or the $3^{\prime}$-UTR region of Cox-2 with six mutant nucleotides. The histogram in Figures 2D and 3D showed that the enzyme activity was not significantly reduced in cells transfected with 
miR-203

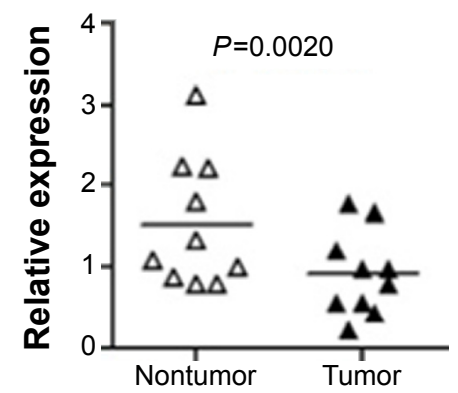

miR-10a

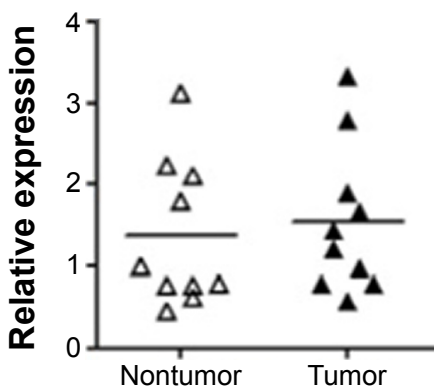

miR-125a

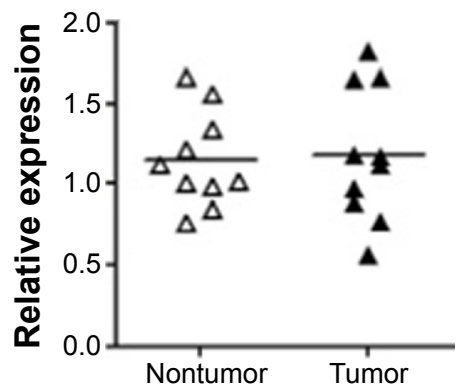

miR-29a

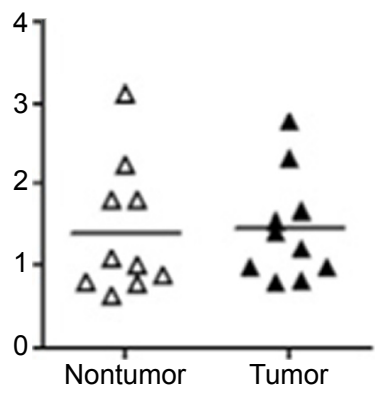

miR-16

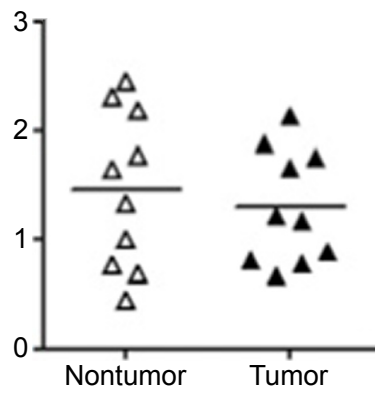

miR-106

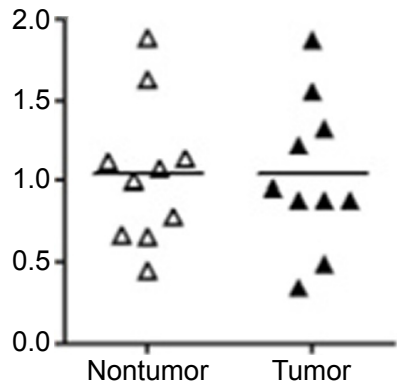

miR-30a

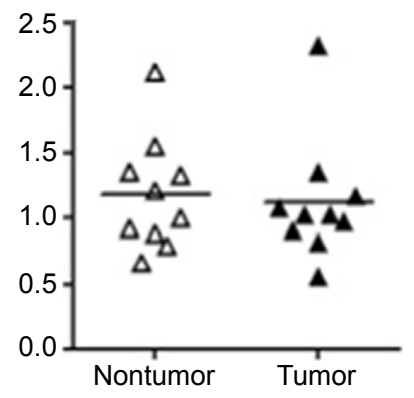

miR-423

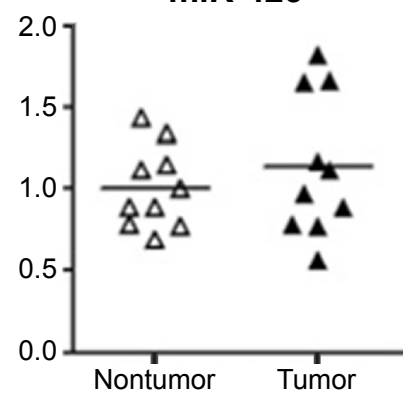

miR-93

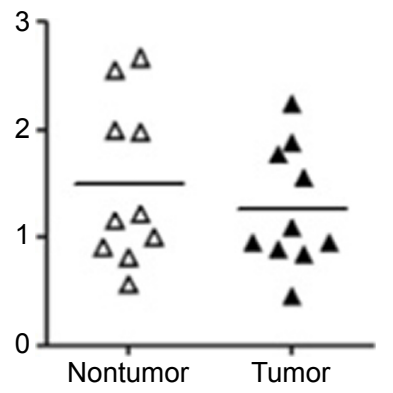

Figure I The expression of miR-203 was downregulated in LSCC tissues.

Notes: Total RNA was extracted from tissues samples by using TRIzol reagent according to the manufacturer's instructions. Random six RNA samples were mixed as one sample for the detection of target molecules. The expression of miRNAs was detected by TaqMan miRNA RT-Real-Time PCR. The U6 snRNA was used for normalization. Each sample in each group was measured in triplicate, and the experiment was repeated at least three times for the detection of miRNAs. Student's $t$-test was used to analyze the expression of candidate miRNAs in tumor and nontumor groups, and $P<0.05$ was considered as statistically significant.

Abbreviations: LSCC, laryngeal squamous cell carcinoma; miRNA, microRNA; PCR, polymerase chain reaction; snRNA, small nuclear RNA.

Table I Correlation between miR-203 and clinicopathological parameters

\begin{tabular}{lll}
\hline Characteristics $(\mathbf{n})$ & miR-203 expression (T/N ratio) & P-value \\
\hline $\begin{array}{l}\text { Sex } \\
\quad \text { Male (4I) }\end{array}$ & $0.613 \pm 0.073$ & \\
$\quad$ Female (19) & $0.822 \pm 0.174$ & \\
Age (years) & & 0.913 \\
$\quad \geq 60(35)$ & $0.665 \pm 0.086$ & \\
$\quad<60(25)$ & $0.699 \pm 0.134$ & \\
T classification & & 0.037 \\
TI-2 (28) & $0.85 I \pm 0.132$ & \\
T3-4 (32) & $0.529 \pm 0.0703$ & \\
Lymph node metastasis & & 0.0469 \\
$\quad$ Negative (29) & $0.832 \pm 0.119$ & \\
$\quad$ Positive (3I) & $0.537 \pm 0.0852$ & \\
Primary site & & \\
$\quad$ Glottic (27) & $0.693 \pm 0.126$ & \\
Supraglottic (33) & $0.669 \pm 0.0890$ & \\
\hline
\end{tabular}

miR-control compared with miR-203 mimic $(P>0.05)$. These data indicate that $m i R-203$ may suppress the expression of VEGFA and Cox-2 through binding to seed sequence at the 3'-UTR of VEGFA and Cox-2.

To further examine whether endogenous expression of VEGFA and Cox-2 is suppressed by $m i R-203$, Hep- 2 cells were transfected with $m i R-203$ mimics or inhibitor. VEGFA and Cox-2 protein levels were detected by Western blot after 48 hours of transfection. Compared with the corresponding control, the levels of VEGFA and Cox-2 proteins were significantly suppressed by $m i R-203$ mimics and upregulated by miR-203 inhibitor in Hep-2 cells (Figures 2E and 3E). These results indicated that $m i R-203$ repressed the endogenous expression of VEGFA and Cox-2 in the laryngeal cancer cells by directly targeting 3 '-UTR. 


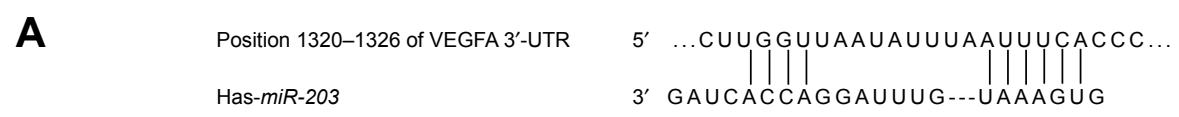

B

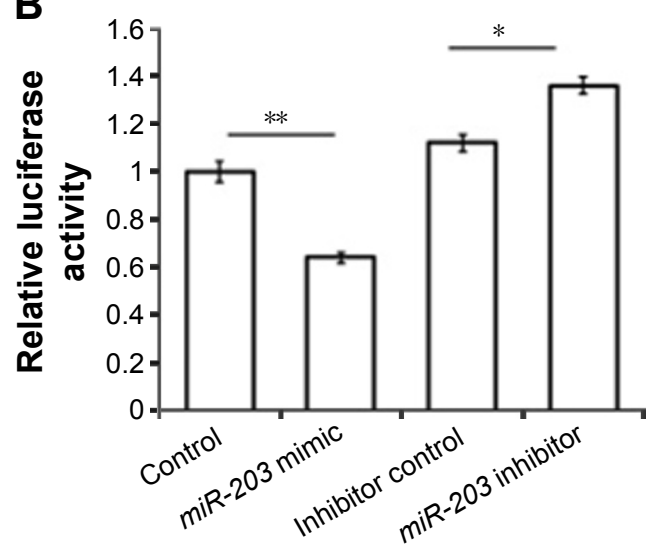

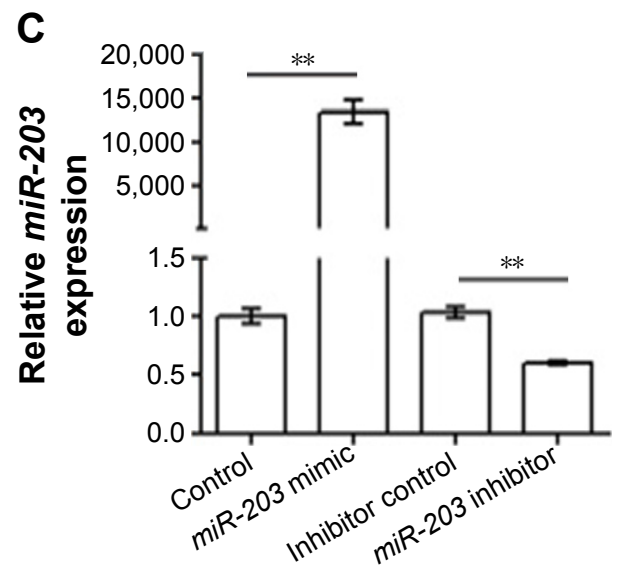

D Position 1320-1326 of $5^{\prime}$... CUUCGUUAAUAUUUAAUAaGACCC... mutant VEGFA 3'-UTR Has-miR-203 3'GAUCACCAGGAUUUG...UAAAGUG
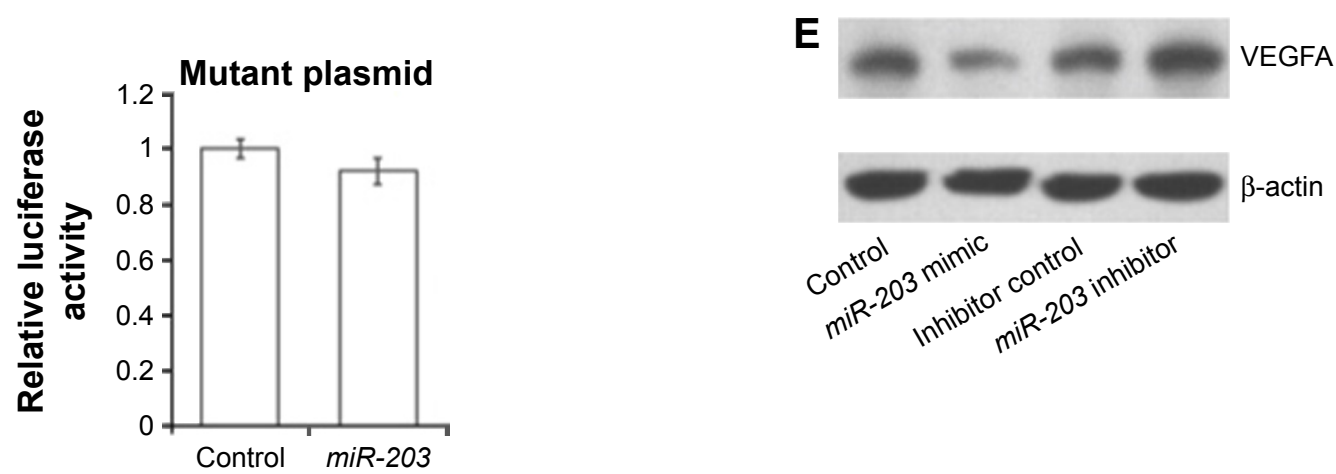

Figure 2 VEGFA is a direct target of miR-203.

Notes: (A) A schematic diagram for the predicted interaction between miR-203 and the $3^{\prime}$-UTR of VEGFA mRNA. (B) pGL3-VEGFA was cotransfected with miR-203 mimic or inhibitor into HEK293T cells for dual-luciferase assay. (C) The expression of miR-203 in each group was detected by using qRT-PCR. (D) Mutation clone of four nucleotides was constructed to identify the binding site of miR-203. The results were analyzed by Student's $t$-test, and $P<0.05$ was considered as statistically significant. $* P<0.05$ and $* * P<0.01$. (E) Hep-2 cells were transfected with miR-203 mimic or inhibitor; 48 hours later, the endogenous VEGFA protein level was detected by Western blot. Abbreviations: VEGFA, vascular endothelial growth factor A; UTR, untranslated region; mRNA, messenger RNA; qRT-PCR, quantitative reverse transcription-polymerase chain reaction.

\section{Expression of VEGFA and Cox-2 is negatively correlated with miR-203 level in vivo}

To further examine the relationship between miR-203 level and its target genes in vivo, we detected the expression of $m i R-203$ in every independent sample, and meanwhile, the protein levels of VEGFA and Cox-2 were also detected by Western blot. The relative band intensity was quantified by using ImageJ software (National Institutes of Health [NIH] Bethesda, MD, USA) with $\beta$-actin as the loading control. Analyzed with the expression of $m i R-203$, VEGFA, and Cox-2, we found inverse correlations between the expression levels of miR-203 and VEGFA or Cox-2 in 60 clinical samples of LSCC. Low levels of $m i R-203$ were associated with high expression of VEGFA (Pearson's correlation, $r=-0.398 ; P<0.01$; Figure 4A and B) and Cox-2 (Pearson's correlation, $r=-0.302 ; P<0.05$; Figure $4 \mathrm{C}$ and $\mathrm{D})$.

\section{miR-203 suppresses proliferation, migration, and invasion of laryngeal cancer cells}

To further test whether miR-203 may execute tumor-suppressive functions by targeting VEGFA and Cox-2, we investigated the effect of $m i R-203$-mediated cell proliferation by MTT assay in Hep-2 cells (Figure 5A). The cell proliferation was significantly reduced by $m i R-203$ mimic, $~ 54.8 \%$. Meanwhile, the cell proliferation was significantly upregulated by miR-203 inhibitor in Hep-2 cells, $~ 33.1 \%$. 

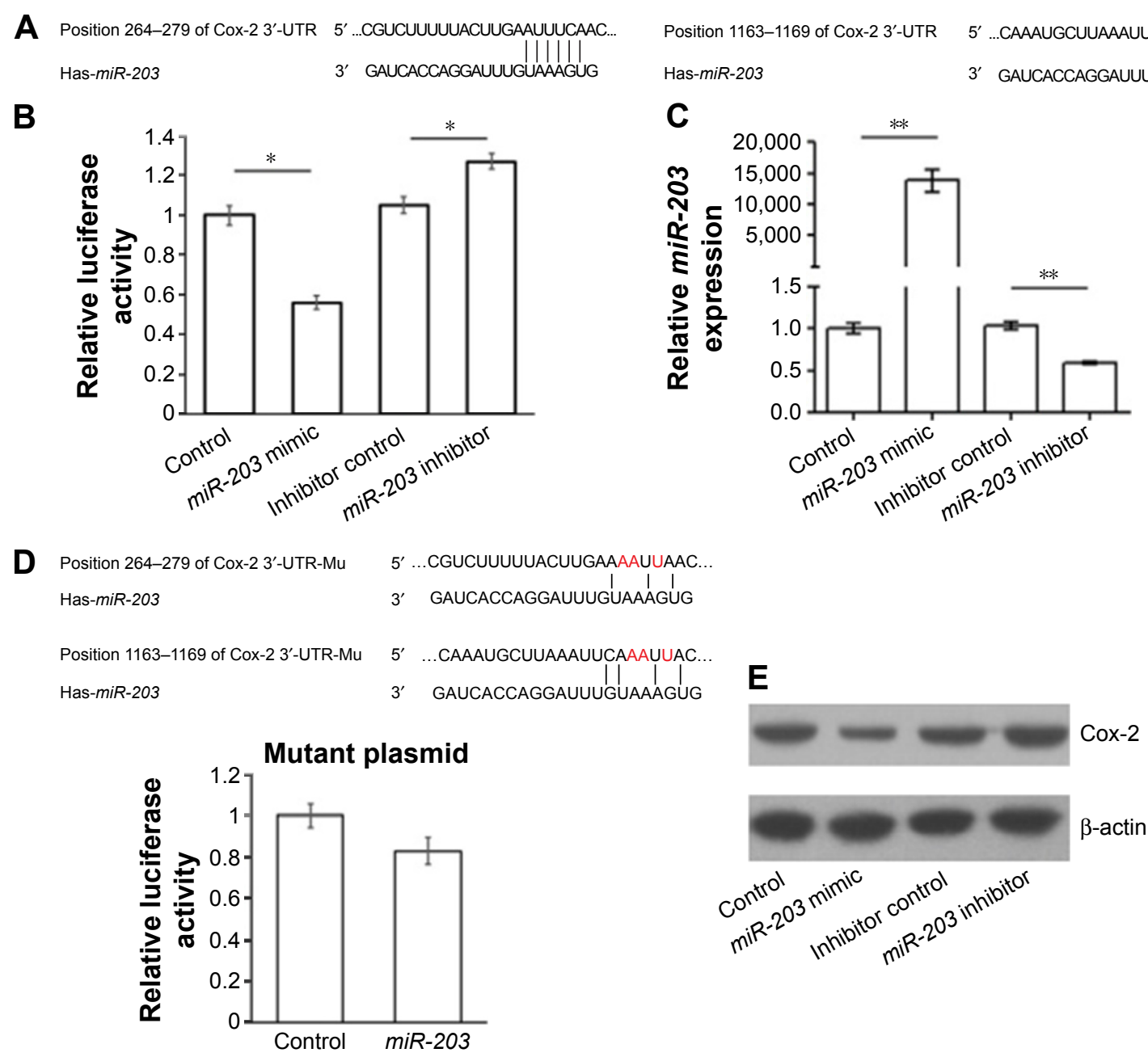

Figure 3 Cox-2 is a direct target of miR-203.

Notes: (A) A schematic diagram for the predicted interaction between miR-203 and the 3'-UTR of Cox-2 mRNA. (B) pGL3-Cox-2 was cotransfected with miR-203 mimic or inhibitor into HEK293T cells for dual-luciferase assay. (C) The expression of miR-203 in each group was detected by using qRT-PCR. (D) The mutation clone of six nucleotides was constructed to identify the binding site of miR-203. The results were analyzed by Student's $t$-test, and $P<0.05$ was considered as statistically significant. $* P<0.05$ and $* * P<0.01$. (E) Hep-2 cells were transfected with miR-203 mimic or inhibitor; 48 hours later, the endogenous Cox-2 protein level was detected by Western blot. Abbreviations: Cox-2, cyclooxygenase-2; UTR, untranslated region; mRNA, messenger RNA; qRT-PCR, quantitative reverse transcription-polymerase chain reaction.

To further confirm whether miR-203 represses cell proliferation by targeting VEGFA and Cox-2, we cotransfected VEGFA or Cox-2 expression vector with miR-203 mimic into Hep-2 cells. As shown in Figure 5B, VEGFA and Cox-2 expression vector can partially rescue the repressed cell proliferation caused by $m i R-203$ overexpression, which means that $m i R-203$ suppresses the ability of cell proliferation partially through targeting VEGFA and Cox-2.

In order to further research the roles of $m i R-203$ in controlling the metastasis of laryngeal cancer, we analyzed the effects of $m i R-203$ on the migratory and invasive behaviors of Hep-2 cells. As shown in Figure 5C and E, the migration and invasion capacities were significantly suppressed in cells transfected with miR-203 mimic compared with control $(P<0.05)$. In the contrary, the number of migrated and invaded cells was significantly upregulated by the $m i R$ 203 inhibitor $(P<0.05)$. Meanwhile, VEGFA overexpression can partially rescue the repressed cell migration and invasion capacity caused by miR-203 $(P<0.05)$ Figure 5D and F. Cox-2 overexpression can also slightly rescue the cell migration and invasion capacity, but the differences were not significant $(P>0.05)$ Figure 5D and $\mathrm{F}$. These results suggest that the level of $m i R-203$ is closely associated with the metastasis of laryngeal cancer.

\section{Discussion}

The development of LSCC is a multistep process involving multiple factors. miRNAs, a group of important negative regulator of gene expression, have also been confirmed to be involved in the LSCC pathogenesis. In the present study, 


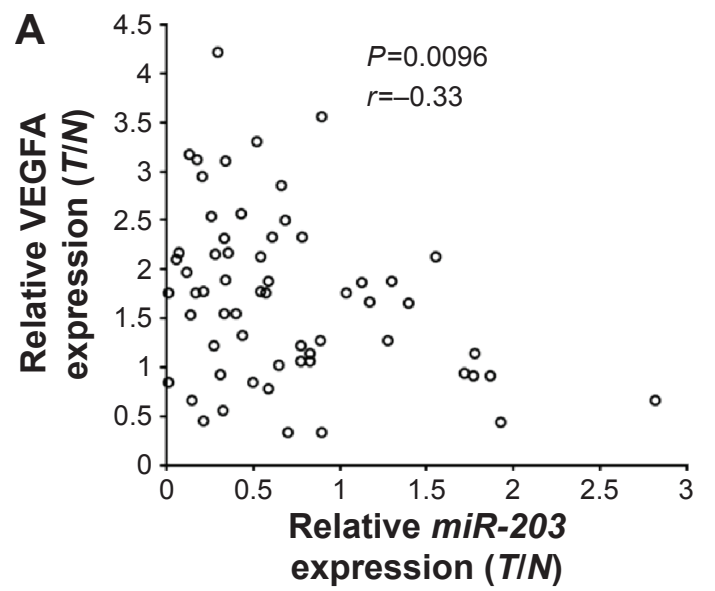

B
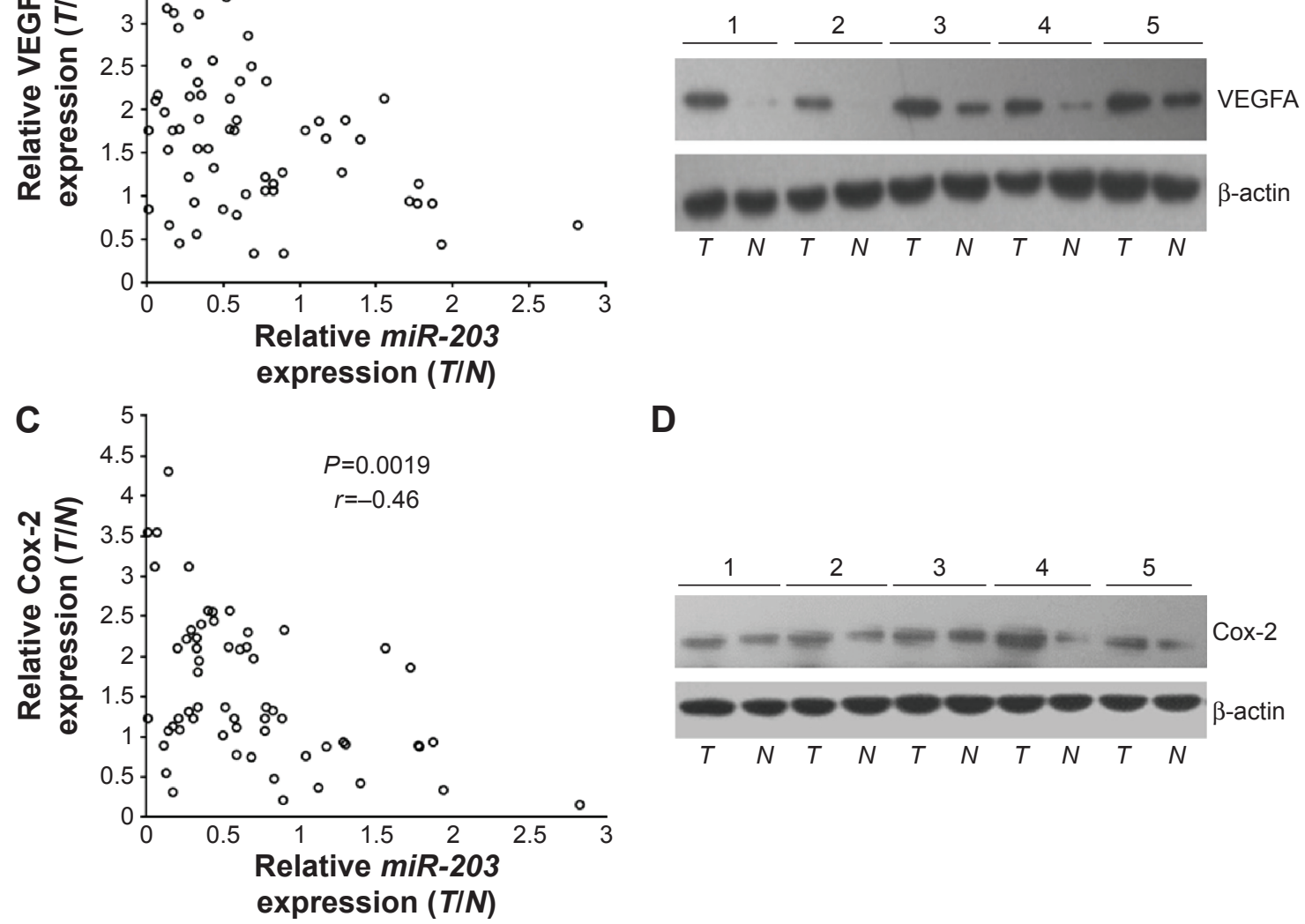

Figure 4 The correlation between the expression of miR-203 and the levels of VEGFA or Cox-2 protein in LSCC patients.

Notes: (A) The expression of miR-203 in every tumor and adjacent nontumor samples was detected using stem-loop qRT-PCR. The expression of VEGFA was detected by Western blot. To evaluate the expression of VEGFA, the band intensity of Western blot was semiquantitatively calculated. Correlation analysis was used to analyze the relationship between the expression of miR-203 and VEGFA. (B) An example of the Western blot results detecting VEGFA expression in tissues. (C) Correlation analysis between the expression of miR-203 and Cox-2. (D) An example of the Western blot results detecting Cox-2 expression in tissues.

Abbreviations: VEGFA, vascular endothelial growth factor A; Cox-2, cyclooxygenase-2; LSCC, laryngeal squamous cell carcinoma; qRT-PCR, quantitative reverse transcription-polymerase chain reaction.

we compared the expression of nine selected miRNAs in the LSCC tissues and adjacent nontumor tissues. We found that the expression of $m i R-203$ was significantly reduced in the LSCC tissues. Predicted by using bioinformatics tools, we found that VEGFA and Cox-2 might be the direct targets of $m i R-203$. By subsequent determination through dual-luciferase assay and Western blot, we confirmed that miR-203 suppresses the expression of VEGFA and Cox-2 by directly targeting 3 '-UTR. Meanwhile, by analyzing the relationship between $m i R-203$ and VEGFA in clinical tissue samples, we found that a negative correlation existed in the expression of $m i R-203$ and VEGFA. Similarly, the expression of $m i R-203$ and Cox-2 also had a negative correlation. Subsequently, in vitro functional study indicated that $m i R$ 203 played as a tumor suppressor by repressing proliferation, migration, and invasion of Hep-2 cells. The overexpression of VEGFA partially rescued the effect of overexpressed $m i R-203$. Overexpressed Cox-2 partially rescued the effect of $m i R-203$ on the proliferation of Hep-2 cell but not on the cell migration and invasion capacity. These results indicated that $m i R-203$ plays as a tumor suppressor in LSCC, partially by regulating VEGFA and Cox-2.

Although $m i R-203$ has been reported to be upregulated in some kinds of tumors, ${ }^{5,14}$ it is widely accepted that $m i R-203$ functions as a tumor suppressor and has been downregulated especially in head and neck cancer, prostate cancer, gastric cancer, and colon cancer. ${ }^{15-17}$ Attempts to validate $m i R-203$ target genes have increasingly been made to investigate the functional role of $m i R-203$ in carcinogenesis. In this study, we identified for the first time that VEGFA and Cox-2 are the direct targets of $m i R-203$. The function of VEGFA is related to not only regulating vasculogenesis and angiogenesis but also affecting the tumor microenvironment. Cox-2 has prostaglandin (PG) hydroperoxidase activity to synthesize 
A

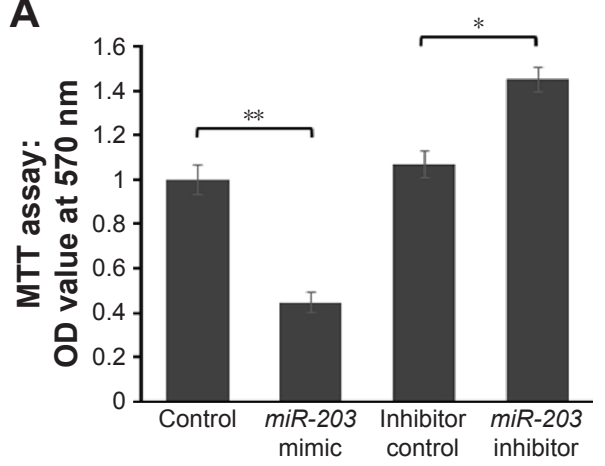

C

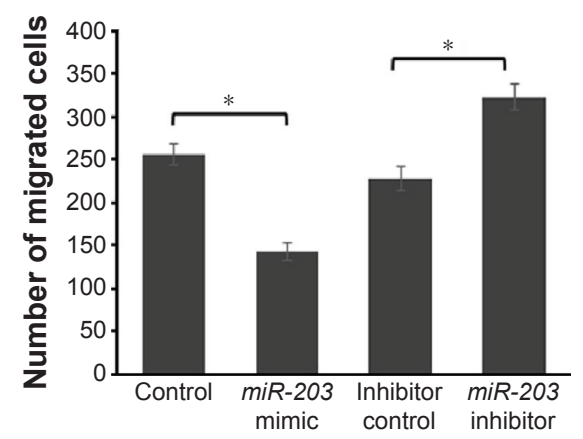

E

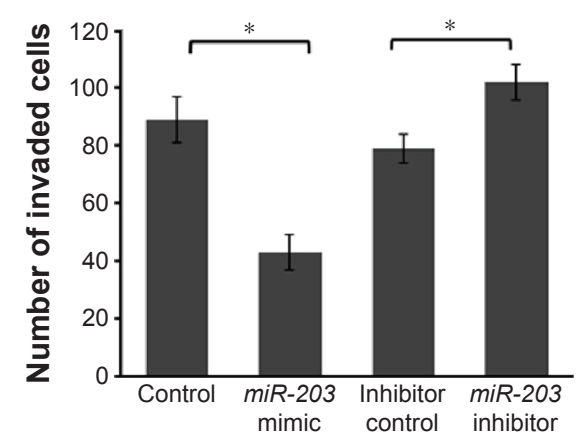

B

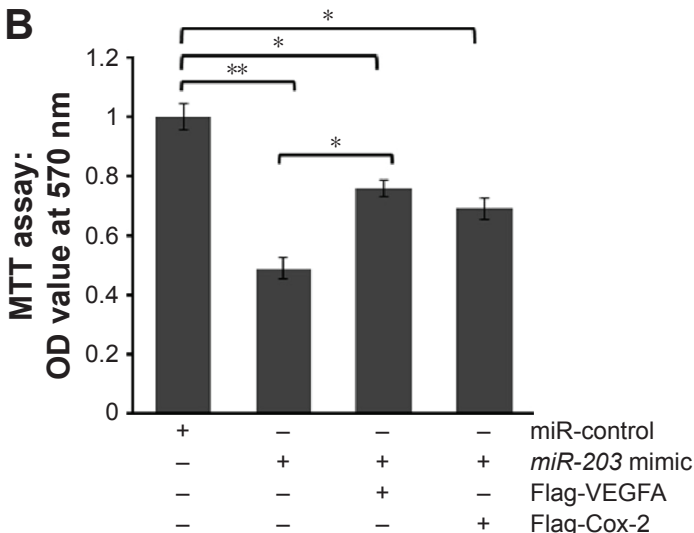

D

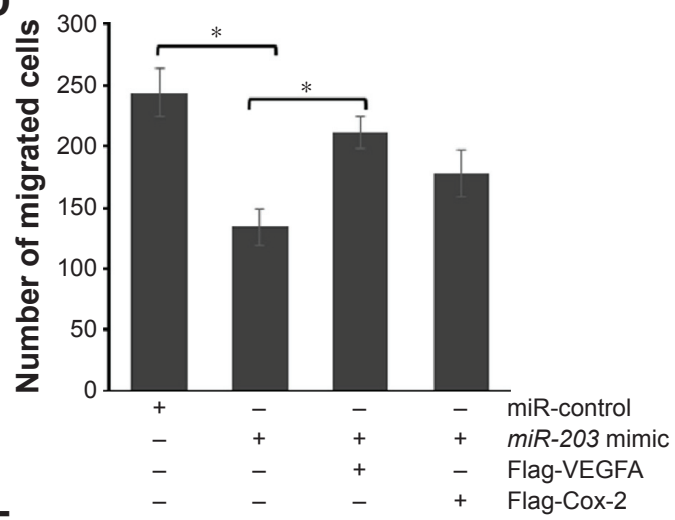

F

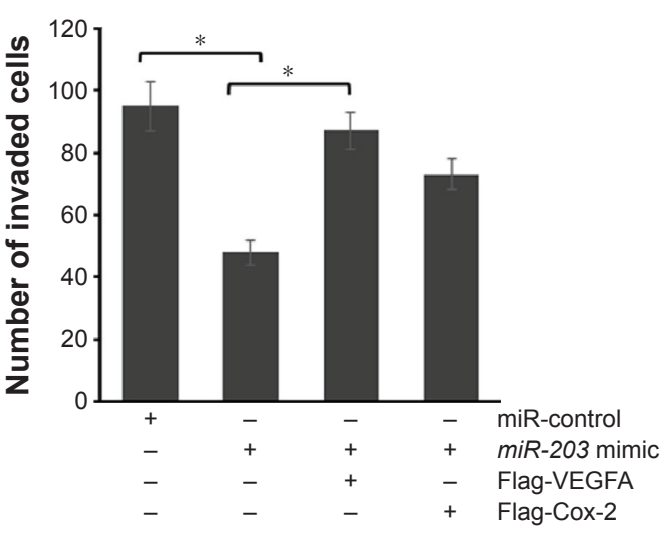

Figure 5 MiR-203 functions as a tumor suppressor via repression of cancer proliferation, migration, and invasion.

Notes: (A and B) Hep-2 cells were seeded in 96 -well plates at a low density $\left(5 \times 10^{3}\right)$ in the DMEM culture and allowed to attach overnight. The cells were then transfected with miR-203 mimic or inhibitor, with sequence scrambled single-strand or double-strand short RNA as control. MTT assay was employed for detecting the cell proliferation after 48 hours of transfection. (C and D) For migration assays, Hep-2 cells were transfected with the miR-203 mimic or inhibitor with scramble RNA as control. The transfected cells were harvested and subjected to the following assays after 48 hours of transfection. The transfected cells were seeded in an $8.0 \mathrm{~mm}$ pore membrane chamber. Following a I2-hour incubation period, the cells that passed through the membrane to attach to the bottom of membrane were fixed and stained with hematoxylin and eosin. The cells were scraped and removed from the top of chamber. The membranes were mounted on cover slides, and the cells were counted. Cell migration was quantified by counting the amount of cells passing through the pores from five different fields per sample at I00X selected in a random manner. (E and $\mathbf{F}$ ) Cell invasion assays were carried out using modified Boyden chambers in 24-well tissue culture plates at $5 \times 10^{4}$ cells/well.All experiments were performed in duplicate. The results were analyzed using Student's $t$-test, and $P<0.05$ was considered statistically significant. $* P<0.05$ and $* * P<0.01$.

Abbreviations: DMEM, Dulbecco's Modified Eagle's Medium; MTT, 3-(4,5-dimethylthiazol-2-yl)-2,5-diphenyltetrazolium bromide; OD, optical density; VEGFA, vascular endothelial growth factor A; Cox-2, cyclooxygenase-2.

PGH2 from PGG2, and the expression of Cox-2 is induced during inflammation, cell proliferation, and differentiation. COX-2 levels have been found to be elevated in various tumors. ${ }^{18-20}$ In this study, we confirmed that negative correlations existed between the expression of $m i R-203$ and VEGFA or Cox-2, which contributes to understanding the mechanism of the higher level of VEGFA and Cox-2 in the LSCC tissues.

\section{Conclusion}

$m i R-203$ functions as a tumor suppressor via targeting VEGFA and Cox-2, and downregulated miR-203 expression 
contributes to LSCC carcinogenesis through enhanced tumor cell proliferation, migration, and invasion.

\section{Disclosure}

The authors report no conflicts of interest in this work.

\section{References}

1. Ahmad Kiadaliri A, Jarl J, Gavriilidis G, Gerdtham UG. Alcohol drinking cessation and the risk of laryngeal and pharyngeal cancers: a systematic review and meta-analysis. PLoS One. 2013;8(3):e58158.

2. Ferlay J, Shin HR, Bray F, Forman D, Mathers C, Parkin DM. Estimates of worldwide burden of cancer in 2008: GLOBOCAN 2008. Int J Cancer. 2010;127(12):2893-2917.

3. Wu WK, Lee CW, Cho CH, et al. MicroRNA dysregulation in gastric cancer: a new player enters the game. Oncogene. 2010;29(43): 5761-5771.

4. Nicoloso MS, Spizzo R, Shimizu M, Rossi S, Calin GA. MicroRNAs - the micro steering wheel of tumour metastases. Nat Rev Cancer. 2009;9(4): 293-302.

5. Ikenaga N, Ohuchida K, Mizumoto K, et al. MicroRNA-203 expression as a new prognostic marker of pancreatic adenocarcinoma. Ann Surg Oncol. 2010;17(12):3120-3128.

6. Izumchenko E, Chang X, Michailidi C, et al. The TGFbeta-miR200-Mig6 pathway orchestrates the EMT-associated kinase switch that induces resistance to EGFR inhibitors. Cancer Res. 2014;74(14):3995-4005.

7. Hui AB, Lenarduzzi M, Krushel T, et al. Comprehensive MicroRNA profiling for head and neck squamous cell carcinomas. Clin Cancer Res. 2010;16(4):1129-1139.

8. Avissar M, Christensen BC, Kelsey KT, Marsit CJ. MicroRNA expression ratio is predictive of head and neck squamous cell carcinoma. Clin Cancer Res. 2009;15(8):2850-2855.

9. Zhang T, Liu M, Wang C, Lin C, Sun Y, Jin D. Down-regulation of MiR-206 promotes proliferation and invasion of laryngeal cancer by regulating VEGF expression. Anticancer Res. 2011;31(11):3859-3863.
10. Agarwal V, Bell GW, Nam J, Bartel DP. Predicting effective microRNA target sites in mammalian mRNAs. eLife, 4:e05005.

11. Sullu Y, Gun S, Atmaca S, Karagoz F, Kandemir B. Poor prognostic clinicopathologic features correlate with VEGF expression but not with PTEN expression in squamous cell carcinoma of the larynx. Diagn Pathol. 2010;5:35.

12. Chen YF, Luo RZ, Li Y, et al. High expression levels of COX-2 and P300 are associated with unfavorable survival in laryngeal squamous cell carcinoma. Eur Arch Otorhinolaryngol. 2013;270(3):1009-1017.

13. Bayazit YA, Buyukberber S, Sari I, et al. Cyclo-oxygenase 2 expression in laryngeal squamous cell carcinoma and its clinical correlates. ORL J Otorhinolaryngol Relat Spec. 2004;66(2):65-69.

14. Iorio MV, Visone R, Di Leva G, et al. MicroRNA signatures in human ovarian cancer. Cancer Res. 2007;67(18):8699-8707.

15. Chiang Y, Song Y, Wang Z, et al. Aberrant expression of miR-203 and its clinical significance in gastric and colorectal cancers. Gastrointest Surg. 2011;15(1):63-70.

16. Tian L, Li M, Ge J, et al. MiR-203 is downregulated in laryngeal squamous cell carcinoma and can suppress proliferation and induce apoptosis of tumours. Tumour Biol. 2014;35(6):5953-5963.

17. Hailer A, Grunewald TG, Orth M, et al. Loss of tumor suppressor mir-203 mediates overexpression of LIM and SH3 Protein 1 (LASP1) in high-risk prostate cancer thereby increasing cell proliferation and migration. Oncotarget. 2014;5(12):2918-4153.

18. Shibata M, Kodani I, Osaki M, et al. Cyclo-oxygenase- 1 and -2 expression in human oral mucosa, dysplasias and squamous cell carcinomas and their pathological significance. Oral Oncol. 2005;41(3):304-312.

19. Mohan S, Epstein JB. Carcinogenesis and cyclooxygenase: the potential role of COX-2 inhibition in upper aerodigestive tract cancer. Oral Oncol. 2003;39(6):537-546.

20. Gallo O, Masini E, Bianchi B, Bruschini L, Paglierani M, Franchi A. Prognostic significance of cyclooxygenase-2 pathway and angiogenesis in head and neck squamous cell carcinoma. Hum Pathol. 2002;33(7): 708-714.
OncoTargets and Therapy

\section{Publish your work in this journal}

OncoTargets and Therapy is an international, peer-reviewed, open access journal focusing on the pathological basis of all cancers, potential targets for therapy and treatment protocols employed to improve the management of cancer patients. The journal also focuses on the impact of management programs and new therapeutic agents and protocols on

\section{Dovepress}

patient perspectives such as quality of life, adherence and satisfaction. The manuscript management system is completely online and includes a very quick and fair peer-review system, which is all easy to use. Visit http://www.dovepress.com/testimonials.php to read real quotes from published authors. 